\title{
APPLICATION OF RAW VOLCANIC ROCK FOUND IN ETNA VALLEY AS AN ADSORBENT OF CHROMATES, ARSENATES AND SELENATES
}

\author{
Mladen Bugarčicic ${ }^{1 *}$, Milan Milivojević ${ }^{2}$, Aleksandar Marinković ${ }^{2}$, Branislav \\ Markovićl, Miroslav Sokićl ${ }^{1}$, Nela Petronijević ${ }^{l}$, Jovica Stojanovićl \\ ${ }^{1}$ Institute for Technology of Nuclear and Other Mineral Raw Materials, \\ 86 Franchet d'Esperey Street, P.O. Box 390, 11000 Belgrade, Serbia \\ ${ }^{2}$ University of Belgrade, Faculty of Technology and Metallurgy, 4 Karnegijeva \\ Street, Belgrade, Serbia
}

Received 11.06.2018

Accepted 26.06.2018

\begin{abstract}
This paper aims to determine the potential of volcanic rock found in Etna valley as an adsorbent of heavy metals in anionic form (chromates, arsenates, and selenates). Characterization of the volcanic rock was done with chemical methods (AAS, AES, gravimetric analysis, XRF), physicochemical methods (XRD, FTIR, SEM, DTA, DTG) and physical methods (porosity measurement, Microscopy in transmitted light). Also, equilibrium adsorption capacity was determined. All the results of adsorption capacity were satisfying considering the mineral composition, granulation, and porosity. The removal efficiency of chromates was the biggest (above $30 \%$ ) with adsorption capacity

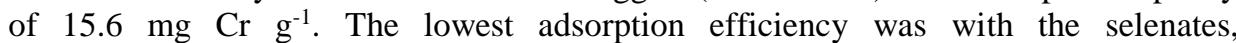
approximately $18 \%$.
\end{abstract}

Keywords: adsorption; anionic heavy metals; volcanic rock; Etna.

\section{Introduction}

Water pollution is one of the most serious environmental problems; this is due to massive consumption of water for industrial processes, irrigation, public water supplies and as a cooling fluid of electric power plants [1]. Massive consumption of fresh water together with waste disposal in air, soil, and water has led to massive water pollution. Among toxic substances, heavy metals are one of the most significant threats for Biosystems considering the ATSDR (Agency for Toxic Substances and Disease Registry) statistics [2]. Already contaminated water together with wastewater needs to be conveniently treated, so environmental disasters are prevented. The available

* Corresponding author: Mladen Bugarčić,m.bugarcic@itnms.ac.rs 
methods being used for treating wastewater rich in heavy metals include precipitation, coagulation and flocculation, ion exchange, membrane filtration, adsorption and other alternative methods. Among them, adsorption is favored for its efficiency, economy, minimal regulating parameters and a possibility of using cheap materials as adsorbents. Utilization of the non-modified raw material as an adsorbent of heavy metals from water solution would be beneficial for solving the capital issue of water pollution. Heavy metal water pollution is a problem for almost every single country, so shortly, vast amounts of adsorbents would be needed to reduce the level of water pollutants. Considering this fact, it is necessary to find available, abundant and cheap raw material which can be used as adsorbent as is or with minor processing. Plenty of mineral raw material fulfill all requirements of the potential cheap adsorbent. Today the most prevalent research of materials which may be noted as cheap adsorbents are natural alternative materials such as chitosan [3], lignin [4], clays [5, 6], zeolites [7] and waste biomaterials (rice husk [8,9], tea waste [10], wheat straw [11], peach stone [12], various agriculture waste [13]) which are readily available. Currently, there is a high interest in researching the possibility of using other mineral sources as adsorbents such as clays, zeolites, and other porous minerals but shallow interest in researching the natural raw rocks. Particularly interesting natural mineral sources used as adsorbents are those who are porous and may form a chemical bond with molecules of adsorbate. The adsorption mechanism of arsenic on iron and its compounds is well known among arsenic adsorbent community $[14,15]$.

Assuming that volcanic rock found on Etna is rich with iron oxides or other minerals containing iron (assumption made by observation the sample of rock) it was decided to do research which will reveal those assumptions. This paper aims to characterize raw volcanic rock found on Etna, to determine maximum adsorption capacity and to estimate the possibility of using this material without any modification for adsorbing heavy metals in anionic form.

\section{Materials and methods}

The volcanic rock which is the subject of this research was found in Etna valley $\left(37^{\circ} 41^{\prime} 52.9^{\prime \prime} \mathrm{N}, 14^{\circ} 55^{\prime} 32.4^{\prime \prime E}\right) 8^{\text {th }}$ of May 2017. As shown in Fig. 1, this rock is macroporous, and it can be assumed that the red color is attributed to it containing Fe (III) compounds. Chemicals used for adsorption experiments were: deionized water $\left(18{\mathrm{M} \Omega \mathrm{cm}^{-1}}^{-1}\right.$, standard reference solution used for atomic adsorption of As, $\mathrm{Cr}$ and Se mass concentration $100 \mathrm{ppm}$, Accu Trace ${ }^{\mathrm{TM}}$; sodium-hydroxide and hydrochloric acid used for $\mathrm{pH}$ adjustments, Sigma Aldrich.

Equipment used for adsorption experiments were: syringes, syringe filters, burretes, volumetric flasks, pipets, magnetic stirring bars, $10 \mathrm{ml}$ tubes, magnetic stirrer. Methods used for characterization are as followed: XRPD (X-Ray Powder Diffraction); Microscopy in transmitted light; Differential Thermal Analysis (DTA); Differential Thermal Gravimetry (DTG); XRF (X-Ray Fluorescence); SEM (Scanning Electron Microscopy); FTIR (Fourier-Transform Infrared Spectroscopy); AAS (Atomic Absorption Spectroscopy), AES (Atomic Emission Spectroscopy) and gravimetric analysis are used for determining quantitative chemical composition of the silica in the rock sample. 


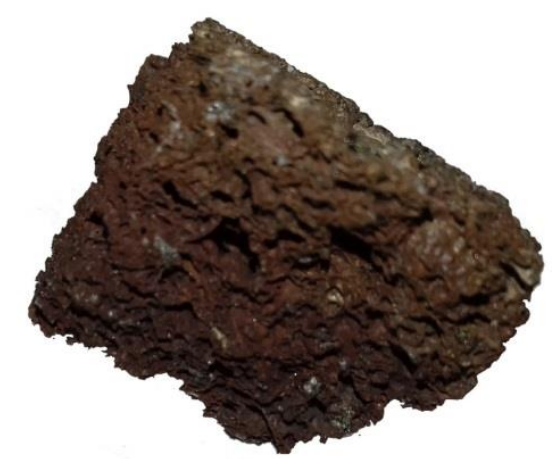

Fig. 1. Volcanic rock specimen used as a material source of investigated samples.

Equipment and its modes used for listed methods are as followed:

Diffractometer Philips PW-1710used for XRPD analysis - automated diffractometer using a $\mathrm{Cu}$ tube operated at $40 \mathrm{kV}$ and $30 \mathrm{~mA}$. The instrument was provided with a diffracted beam curved graphite monochromator and a Xe-filled proportional counter. Measurements were performed at ambient temperature $\left(25^{\circ} \mathrm{C}\right)$. The diffraction data were assembled in the $2 \theta$ Bragg angle range from 4 to $65^{\circ}$, counting for $1 \mathrm{~s}$ (qualitative identification) at every $0.02^{\circ}$ step. The divergence and receiving slits were fixed at 1 and $0.1 \mathrm{~mm}$, respectively.

The polarizing microscope Carl-Zeiss, model "JENAPOL-U" equipped with $10 \times$, $20 \times, 50 \times, 100 \times$ (oil immersion) objectives and a system for a photomicrography ("Axiocam105 color" camera and "Carl Zeiss AxioVision SE64 Rel. 4.9.1." software package with „Multiphase” module) was used for microscope investigations in transmitted light.

Thermo Fisher Scientific Nicolet IS-50 spectroscopy was used for FTIR analysis. The analysis was done in transmission mode in a wavenumber range from 4000 to 400 $\mathrm{cm}^{-1}$ with the resolution of $4 \mathrm{~cm}^{-1}$ in 32 scans. The sample was prepared as the tablet 0.1 mass \% of the powdered together with the KBr p.a. Sigma Aldrich. After spectroscopic measurement spectrogram was corrected: automatic the baseline correction and atmospheric correction (to eliminate signals made by $\mathrm{CO}_{2}$ and $\mathrm{H}_{2} \mathrm{O}$ ).

Thermal analysis was performed on a Netzsch STA 409 EP (Selb, Germany). Samples were heated $\left(20-800{ }^{\circ} \mathrm{C}\right)$ in an air atmosphere with a heating rate of $10^{\circ} \mathrm{C}$ $\min ^{-1}$.

Water solution which was used for determining the content of $\mathrm{Fe}, \mathrm{Al}, \mathrm{Ti}$ and $\mathrm{Mg}$ (AAS) and $\mathrm{Ca}$ (AES) was obtained during the standard gravimetric method for determining silicon-dioxide(DM 10-0/2). Moving the $\mathrm{Sr}$, Na, and $\mathrm{K}$ into water solution was done by a mixture of concentrated perchloric and hydrofluoric acid (equimolar ratio), evaporating until dry and re-dissolving with 4.000 M hydrochloric acid (method DM 10-0/12). Both AAS and AES was done on spectroscope Perkin Elmer AAnalyst 300. Powdered samples of raw volcanic rock were divided into granulometric classes using the sieves (mesh size 500, 300 and $100 \mu \mathrm{m}$ ) sieving was done on dry.

Grounding the sample was performed using the mortar and pestle. To evaluate porosity of every granulometric class the procedure earlier described elsewhere was 
used [16]. Only substances used for this method were 96.4 mass \% ethanol and distilled water. Equipment needed for this simplified porosity determination method was analytical balance (Thermo Fisher Scientific AMF64), ultrasound bath (Vabsonic 1.5L $\mathrm{SH}$ )graduated cylinders, filtering flask, water aspirator (pump). Powdered raw rock samples of each class were needed to be prepared before SEM analysis. The samples were coated with gold (15 nm layer, density $\left.19.32 \mathrm{~g} / \mathrm{cm}^{3}\right)$ for making the electroconducting layer needed for this microscopy method. Observation of the prepared samples was done using a JEOL JSM-6610LV scanning electron microscope (SEM). An acceleration voltage of $20 \mathrm{kV}$ was used. Preparation of sample for the XRF analysis was performed as described in the paper of Takashi [17].

\section{Experimental procedures}

To evaluate porosity, it was measured $10.0000 \mathrm{~g}$ of each granulometric class, $50.0 \mathrm{ml}$ of ethanol sample and put into filtering class. After that it was vacuumed for 15 minutes and put into intro ultrasound bath for 30 minutes, this procedure was done three times. After that, the sample was filtered and dried on ambient condition $\left(25^{\circ} \mathrm{C}\right)$ for 15 minutes. Wet sample was put in a graduated cylinder $(50.0 \mathrm{ml})$ and flooded with 30.0 $\mathrm{ml}$ of ethanol. Measuring the difference between the volume of the ethanol and sample and ethanol previously added we evaluate the volume of the sample without its inner volume of the pores. So the porosity was calculated as (Equation 1):

$$
\varepsilon=\frac{m_{W}-m_{M}}{V^{*} \rho_{S}}
$$

Where $\varepsilon$ is porosity, $m_{W}$ is massa of the wet sample, $m_{M}$ is a mass of dry sample, $V$ is the volume of wet sample calculated as previously described and $\rho_{S}$ is the density of ethanol at ambient condition (index s denotes as solvent, so the method may be done using the other solvents as well). Adsorption experiment was performed preparing the standard solutions:Measuring the $10.0 \mathrm{ml}$ of each standard solution of $\mathrm{As}, \mathrm{Cr}$ and $\mathrm{Se}$ (all the adsorbates were in anionic form) and placed into volumetric flasks of $100.0 \mathrm{ml}$ and diluted with deionized water to the line. So we get water solutions of arsenic, chromium and selenium, mass concentration approximately $10 \mathrm{ppm}$. Potential of hydrogen value $(\mathrm{pH})$ of the diluted solutions were adjusted using the standard hydrochloric acid solution $(\mathrm{c}=0.1000 \mathrm{M})$ and standard sodium - hydroxide solution $(\mathrm{c}=0.1000 \mathrm{M}$ and $\mathrm{c}=1.000 \mathrm{M})$.

The potential of hydrogen of each adsorbate sample was set to 5.00 \pm 0.02 . After preparing the adsorbate adsorption experiment was performed in glass tubes. Mass of the raw rock samples used in adsorption experiments was $1.0 \mathrm{mg}$, the volume of the adsorbate was $5.0 \mathrm{ml}$ (measured with automatic pipets). For the sake of getting credible results, every single adsorption experiment was done with three samples.

Magnetic stirrers were put together in every single glass tube, and the tubes were covered with parafilm and put on a magnetic stirrer for 24 hours. The stirring speed was set to $400 \mathrm{rpm}$ on, and heating wasn't applied. After the adsorption adsorbate was filtrated using the syringes and syringe filters, the filtrate was chemically analyzed on AAS together with $\mathrm{pH}$ adjusted standard solutions, so the values get from analysis were comparable. 
Adsorption capacity was calculated as (Equation 2):

$$
q=\frac{V *\left(c_{0}-c_{E}\right)}{m_{s}}
$$

And removal efficiency was calculated as (Equation 3):

$$
q=\frac{V *\left(c_{0}-c_{E}\right)}{m_{s}}
$$

Where:

$q$ is adsorption capacity

$V$ is the volume of adsorbate

$c_{0}$ is a concentration of $\mathrm{As}, \mathrm{Se}$ and $\mathrm{Cr}$ in samples prior to adsorption

$c_{E}$ is a concentration of $\mathrm{As}, \mathrm{Se}$ and $\mathrm{Cr}$ in samples after adsorption

$m_{S}$ is a mass of the raw rock sample (adsorbent)

Powdered rock samples after adsorption experiments were collected and dried for 24 hours on $30{ }^{\circ} \mathrm{C}$. Afterward they were analyzed by FTIR at the same conditions as the raw rock sample.

\section{Results and discussions}

First analysis done on powdered raw rock sample was XRF, this analysis is primarily qualitative but also may give semi-quantitative results. After this analysis AAS, AES and silicon-dioxide gravimetric method was performed. XRF analysis method didn't yield sufficient results so that a quantitative chemical analysis could be given. In Table 1 is shown chemical composition of the same sample done by AAS, AES, and silicon-dioxide gravimetric method.

Table 1. Summed results of the AAS, AES and $\mathrm{SiO}_{2}$ gravimetry.

\begin{tabular}{lccccccccc}
\hline Component & $\mathrm{SiO}_{2}$ & $\mathrm{Al}_{2} \mathrm{O}_{3}$ & $\mathrm{Fe}$ & $\mathrm{Ca}$ & $\mathrm{Mg}$ & $\mathrm{Na}$ & $\mathrm{K}$ & $\mathrm{Ti}$ & $\mathrm{Sr}$ \\
\hline Mass fraction/ mas \% & 42.45 & 20.86 & 7.77 & 7.24 & 4.62 & 2.47 & 1.21 & 1.30 & 0.59 \\
\hline
\end{tabular}

SEM images of middle granulometric class $(100-300 \mu \mathrm{m})$ are shown in Fig. 2. Depending on magnification specific morphologies may be observed. At the Fig. 2a the smallest channel in sample, $\mathrm{d} \approx 10 \mu \mathrm{m}$, may be observed but those channels are so rare. At the Fig. $2 b$ may be seen one irregular pore shape. In the bottom left corner of Fig. $2 c$ may be observed more often crashed pore, no more than $50 \mu \mathrm{m}$ in diameter. The evaluated porosity of every granulometric class is given in Table 2. May be observed that finer granulometric class has a little bigger porosity, but this is due to an error of the porosity among fine particles (packing bed porosity). The same deviation may be observed in the case of granulometric middle class. 
Table 2. Evaluated porosity in all granulometric classes.

\begin{tabular}{cc}
\hline Granulometric class/ $\mu \mathrm{m}$ & Porosity/ \% \\
\hline$>300$ & 10.23 \\
$100-300$ & 10.85 \\
$<100$ & 11.92 \\
\hline
\end{tabular}

Mineral composition of the raw rock sample based on diffractogram (Fig. 3) showed that major minerals in the samples are: plagioclases and pyroxenes. Albite and anorthite are the most present minerals from plagioclase group, while the pyroxenes (diopside) are less represented. Semi-quantitative composition is: plagioclases $(\approx 85 \%)$ and pyroxenes $(\approx 15 \%)$. Although there is no independent diffraction maximum of olivines (forsterite and fayalite), there is a probability of these minerals existing in the sample composition. Plagioclase is the most present mineral in the sample, considering quantitative chemical analysis, crystallo-chemical formula could be calculated. The chemical formula of that plagioclase mineral was $\left(\mathrm{Ca}_{0.60} \mathrm{Na}_{0.40}\right)\left(\mathrm{Al}_{1.5} \mathrm{Si}_{2.5}\right) \mathrm{O}_{8}$ which is close to the chemical formula of labradorite $\left(\mathrm{Ca}_{0.60} N a_{0.40}\right)\left(\mathrm{Al}_{1.6} S \mathrm{Si}_{2.4}\right) \mathrm{O}_{8}$ so this mineral supposed to be carrier of the adsorption phenomenon. Microphotography's of thin sections of Etna sample are given on Fig. 4a-f. Thermal analysis (DTA/TG) was used to study the thermal properties of the Etna sample. The thermogravimetric (TG) and differential thermal analysis (DTA) curves of the sample are presented on Fig. 5. DTA curve gives more information about events that occurred during the heating the sample. Endothermic event from $92-280^{\circ} \mathrm{C}$ represents water evaporation (mass of loss 1 wt \%). Endothermic event on $516{ }^{\circ} \mathrm{C}$ followed by exothermic event on $581{ }^{\circ} \mathrm{C}$ represent $\mathrm{T}_{\mathrm{g}}$ (glass transition temperature) and $\mathrm{T}_{\mathrm{c}}$ (crystallization temperature) of the olivine respectively [18]. The weak endothermic peak at $824{ }^{\circ} \mathrm{C}$ authors Köhler and Wieden describe it as transformation of high- to low-temperature plagioclases. Same authors haven't found other thermal effects, up to $1000{ }^{\circ} \mathrm{C}$ [19]. The evidence that adsorption occurred on the surface of the mineral is FTIR spectra of the samples after the adsorption experiment, on the Fig. 6 is shown unified FTIR spectra of the powdered rock sample before and after adsorption experiment.
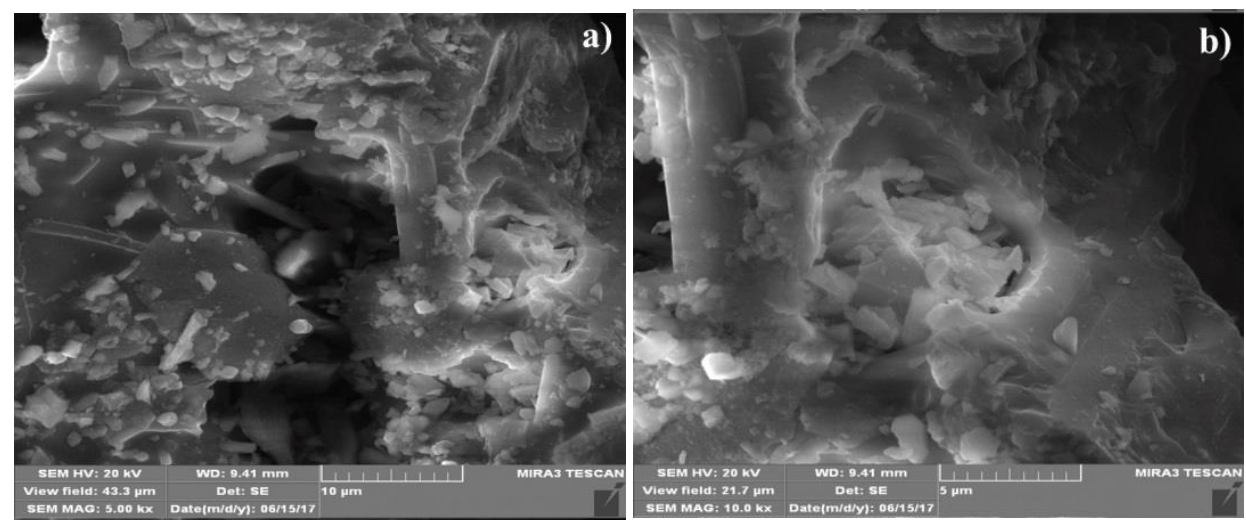


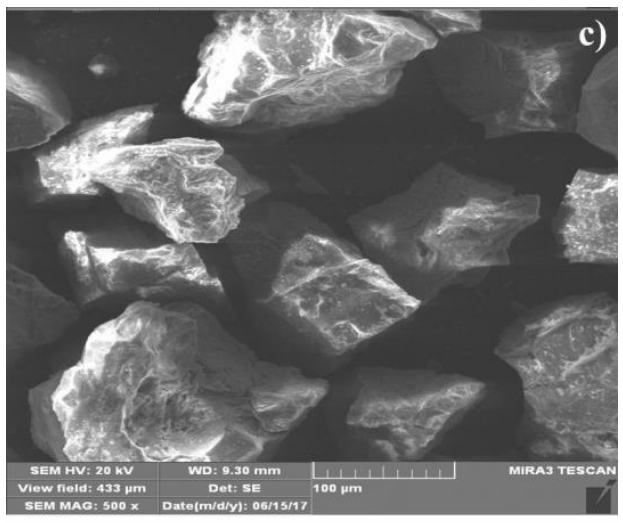

Fig. 2. SEM images of granulometric class from 100 to $300 \mu \mathrm{m}$ : (a) $5 \mathrm{kx}$; (b) $10 k x$; (c) $500 x$.

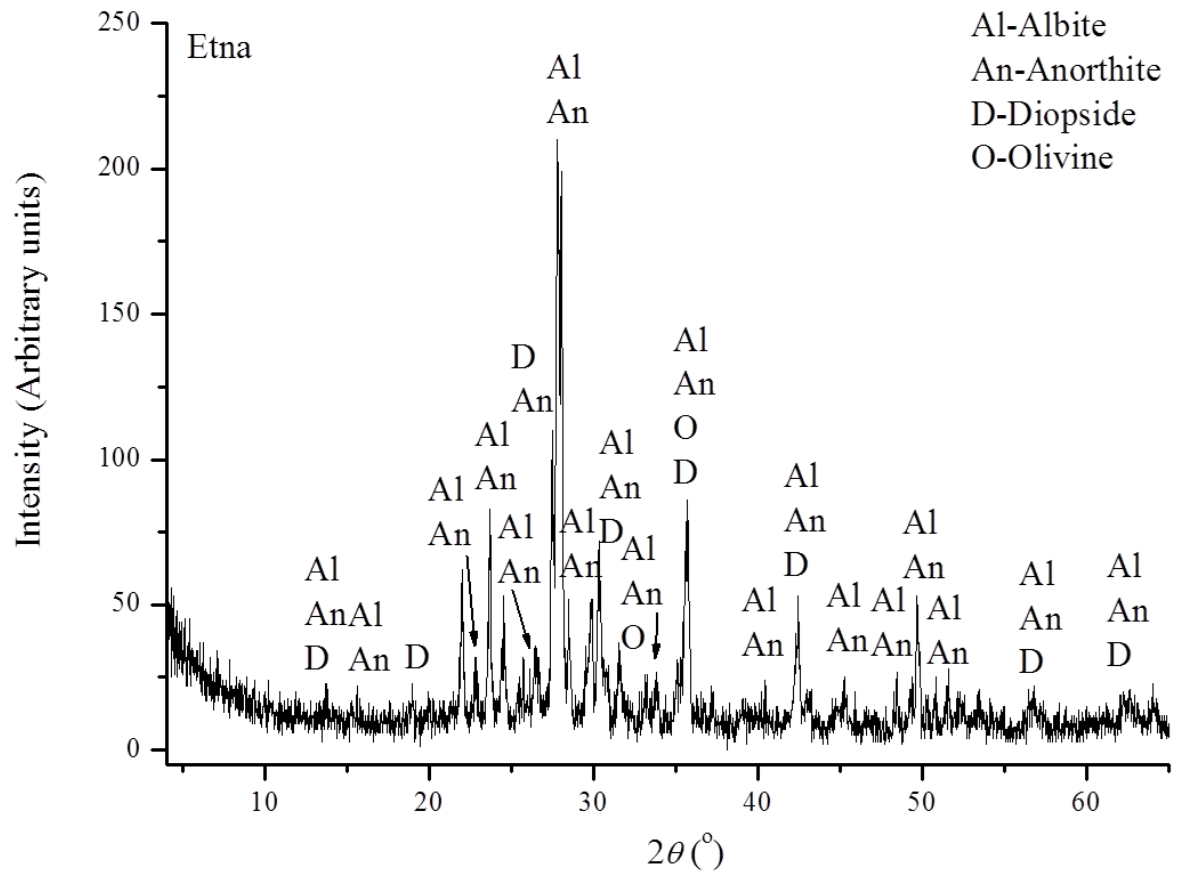

Fig. 3. Diffractogram of the powdered raw rock sample. 


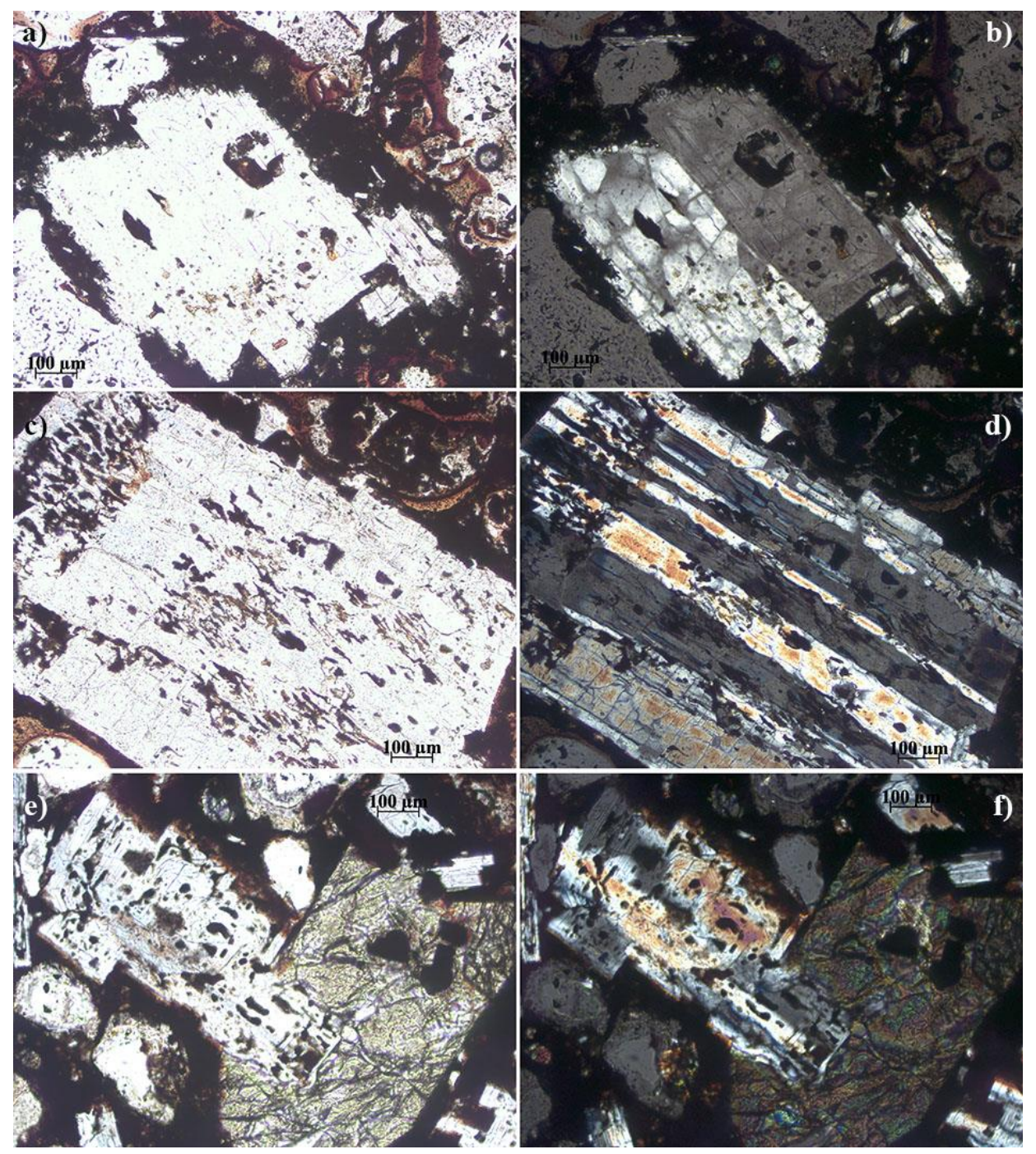

Fig. 4. a) Twin plagioclase crystal, II $N$; b) same motive from a), X N; c) Twinning lamellae of a plagioclase crystal, II $N$; d) same motive from $c), X N ;$ e) Contact of plagioclase (left) and olivine (right) crystals, II $\mathrm{N}$; f) same motive from e), $X N$. 


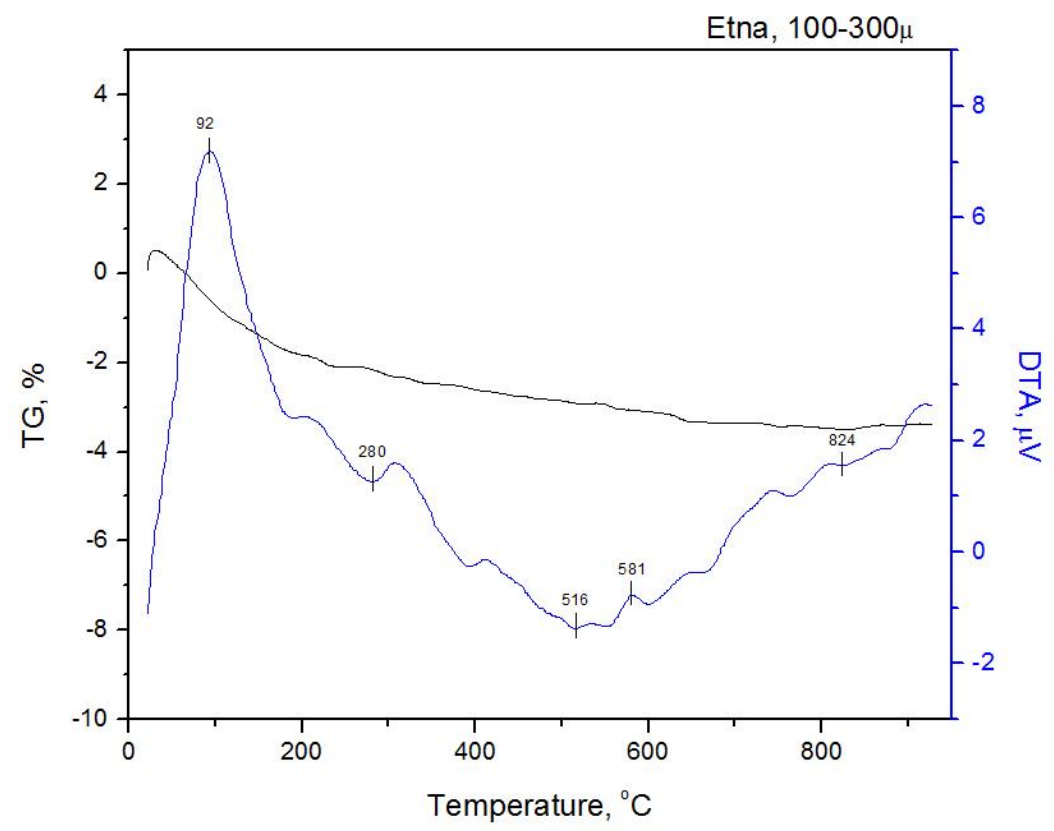

Fig. 5. DTA/TG curves of Etna sample, granulometric middle class (100-300 $\mu \mathrm{m})$.

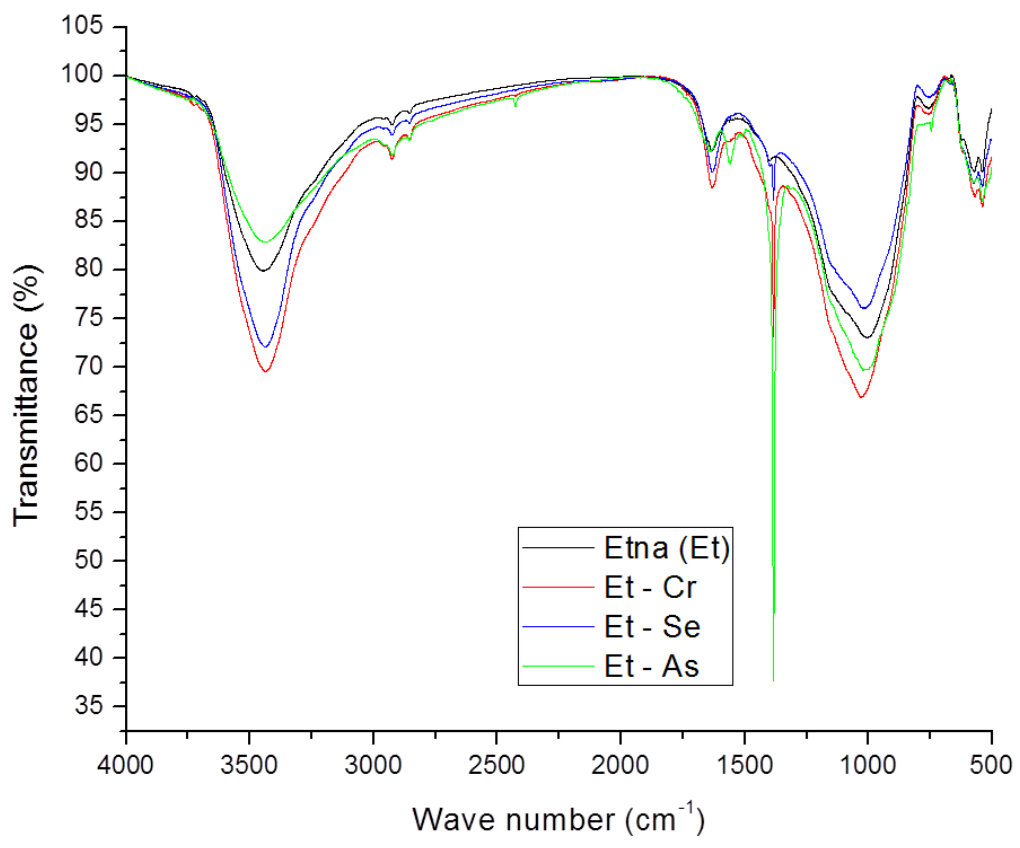

Fig. 6. FTIR diagrams (transmission mode) of raw rock before and after equilibrium adsorption with selenates, chromates, and arsenates. 
Every spectrum has some characteristic peaks, at the $3447 \mathrm{~cm}^{-1}$ and at the $1637 \mathrm{~cm}^{-1}$ first one comes from the stretching of the $\mathrm{O}-\mathrm{H}$ chemical bond and the second one from the bending of the same chemical bond [20,21]. Another one characteristic peak for all samples is on $1005 \pm 2 \mathrm{~cm}^{-1}$ [22] which comes from asymmetric stretching of $\mathrm{T}-\mathrm{O}-\mathrm{T}$ chemical bond $(\mathrm{T}=\mathrm{Si}, \mathrm{Al})$. That peak comes from the chemical bonds in plagioclase and pyroxene minerals; its intensity hasn't changed significantly which means that there is a weak interaction between adsorbate and sample minerals, so physisorption phenomenon has occurred.

A spectrum of the sample after arsenate adsorption has characteristic peaks on $1384 \mathrm{~cm}^{-1}$ and weakening the peak on the $3447 \mathrm{~cm}^{-1}$. First one comes from the exchange of the ionic species of the raw rock with arsenate ions. The second one comes from the exchange of the arsenate ion species with the water molecules [23]. A spectrum of the sample after chromate adsorption has a characteristic peak on $1382 \mathrm{~cm}^{-1}$ which has a bit stronger intensity, so it means that physisorption has occurred [24]. The vibration of the $\mathrm{Se}-\mathrm{O}$ chemical bonds may be found in FTIR spectra at $822,328,856$ and $411 \mathrm{~cm}^{-1}$ [25]. The strongest peak was at $411 \mathrm{~cm}^{-1}$ while others are not much more different than peaks from the original sample. Results showed that the adsorbent (raw volcanic rock) has the most prominent affinity toward chromate ions.

These results were not expected, but they may be explained with the help of Pourbaix diagrams for the arsenic (V), chromium (VI) and selenium (VI) ionic forms present in water at $\mathrm{pH}=5.00$ [26]. On the diagrams may be found that predominant ionic forms for these three are: dihydrogen arsenate ion $\left(\mathrm{H}_{2} \mathrm{AsO}_{4}{ }^{-}\right)$, chromate ion $\left(\mathrm{CrO}_{4}{ }^{2-}\right)$ and hydrogen selenate ion $\left(\mathrm{HSeO}_{4}{ }^{-}\right)$as it is mentioned before physisorption was responsible for removing the adsorbate on the surface of the sample. So ion-ion and ioninducing dipole were the effective interactions responsible for the adsorption. Since the chromate ion has a negative charge of two, its interaction with the surface of the sample is the strongest.

Summered results of adsorption experiments are given in Table 3.

Table 3. Results of adsorption experiments.

\begin{tabular}{|c|c|c|c|c|}
\hline Adsorbate & $\begin{array}{c}\text { Initial } \\
\text { heavy metal } \\
\text { concentration } \\
\text { / ppm }\end{array}$ & $\begin{array}{c}\text { Equilibrium } \\
\text { heavy metal } \\
\text { concentration } \\
\text { /ppm }\end{array}$ & $\begin{array}{l}\text { Removal } \\
\text { efficiency } \\
1 \%\end{array}$ & $\begin{array}{l}\text { Adsorption } \\
\text { capacity } \\
/ \mathrm{mgg}^{-1}\end{array}$ \\
\hline \multirow{3}{*}{$\mathrm{Se}$} & \multirow{3}{*}{10.124} & 8.648 & 14.58 & 7.38 \\
\hline & & 8.064 & 20.35 & 10.3 \\
\hline & & 8.084 & 20.15 & 10.2 \\
\hline \multirow{3}{*}{$\mathrm{Cr}$} & \multirow{3}{*}{10.071} & 6.711 & 33.36 & 16.8 \\
\hline & & 6.811 & 32.37 & 16.3 \\
\hline & & 7.351 & 27.01 & 13.6 \\
\hline \multirow{3}{*}{ As } & \multirow{3}{*}{10.231} & 8.259 & 19.27 & 9.86 \\
\hline & & 7.671 & 25.02 & 12.8 \\
\hline & & 7.231 & 29.32 & 15.0 \\
\hline
\end{tabular}




\section{Conclusions}

Powdered raw volcanic rock found on Etna was characterized in order to get precise information about its composition and morphology, taking in count characterization results (low porosity and presence of non-activated minerals with low adsorption affinity) this mineral source has good adsorbing properties. Mean equilibrium adsorption capacities for $\mathrm{Se}, \mathrm{Cr}$, and As were respectively: 9.29, 15.6, and $12.6 \mathrm{mg} / \mathrm{g}$. The most significant removal efficiency has got for the chromate adsorption $(30.91 \%)$ and the lowest for the selenate $(18.36 \%)$.

However, this mineral source could be attractive as a subject of further research, as it could be modified and activated in order of improving adsorption qualities. Furthermore, the aim of researches should be the investigation of adsorption kinetics together with finding optimal adsorption process parameters. Future promising results are expected with the assistance of nonlinear optimization programs or some other stochastic optimization programs.

\section{Acknowledgments}

This work presents the part of realization in the frame of projects TR 34023 and III 46010, supported by the Ministry of Education, Science and Technological Development of the Republic of Serbia.

\section{References}

[1] OECD, OECD Environmental Data: Compendium 2004, OECD Publishing, Paris, 19 Apr 2005, 102

[2] https://www.atsdr.cdc.gov/SPL/index.html, last access 26th May 2018.

[3] G. McKay, H. S. Blair, A. Findon: Indian J Chem A, 28 (1989) 356-360.

[4] N. V. Efimova, A. P. Krasnopyorova, G. D. Yuhn, A. A. Scheglovskaya: Adsorpt Sci Technol, 35 (2017) 595-601.

[5] A. Đukić, U. Jovanović, T. Tuvić, V. Andrić, J. GrbovićNovaković, N. Ivanović, L. Matović: Ceram Int 39 (2013) 7173-7178.

[6] N. Vidović, I. Jurina, S. D. Škapin, I. Sondi: Appl Clay Sci 48 (2010) 575-580.

[7] M. Kragović, A. Daković, M. Marković, J. Krstić, G. D. Gatta, N. Rotiroti: Appl Surf Sci 283 (2013) 764-774.

[8] M. N. Amin, S. Kaneco, T. Kitagawa, A. Begum, H. Katsumata, T. Suzuki, K. Ohta: Ind Eng Chem Res 45 (2006) 8105-8110.

[9] S. Sobhanardakani, H. Parvizimosaed, E. Olyaie: Environ Sci Pollut Res Int 20 (2013) 5265-5271.

[10] E. Malkoc, Y. Nuhoglu: J Hazard Mater 127 (2005) 120-128.

[11] M. Gorgievski, D. Božić, V. Stanković, N. Štrbac, S. Šerbula: Ecol Eng 58 (2013) 113-122.

[12] Z. R. Lopičić, M. D. Stojanović, T. S. KaluđerovićRadoičić, J. V. Milojković, M. S. Petrović, M. L. Mihajlović, M. L. J. Kijevčanin: J Clean Prod 156 (2017) 95-105.

[13] D. Sud, G. Mahajan, M. P. Kaur: Bioresour Technol 99 (2008) 6017-6027.

[14] M. G. Mostafa, Y-C. Chen, J-H. Jean, C-C. Liu, Y-C. Lee: J Hazard Mater 187 (2011) 89-95.

[15] V. P. Simeonova: Water Supp, 18 (2000) 636-640.

[16] H. Sontheimer, J. C. Crittenden, R. S. Summers: J Am Water Works Assoc (1988) 77-87.

[17] G. Takahashi: Rigaku J, 31 (2015) 26-30. 
[18] P. Jozwiak, J. E. Garbarczyk, M. Wasiucionek, I. Gorzkowska, F. Gendron, A. Mauger, C. M. Julien: Solid State Ionics 179 (2008) 46-50.

[19] A Köhler, P Wieden: Neues Jahrb Mineral Monatsh (1954) 249-252.

[20] G. D. Bromiley, F. Nestola, S. A. T. Redfern, M. Zhang: Geochim Cosmochim Acta 74 (2010) 705-718.

[21] J. T. Kloprogge, L. Hickey, R. L. Frost: J Raman Spectrosc 35 (2004) 967-974.

[22] M. R. Derrick M R, D. Stulik D, J. M. Landry, Infrared Spectroscopy in Conservation Science, J. Paul Getty Trust, United States of America, 1999, 195.

[23] A. J. Roddick-Lanzilotta, A. J. McQuillan, D. Craw: Appl Geochem 17 (2002) 445454.

[24] R. S. Dongre: Bull Mater Sci 39 (2016) 865-874.

[25] M. Malchos, M. Jansen: Z Naturforsch B Chem Sci 53b (1998) 704-710.

[26] N. Takeno, Atlas of Eh-pH diagrams Intercomparison of thermodynamic databases, National Institute of Advanced Industrial Science and Technology, Japan, May 2005, 30, 79, 230.

\section{(c) (7) Creative Commons License}

This work is licensed under a Creative Commons Attribution 4.0 International License. 